\title{
ВмJ Global Health Economic burden of female genital mutilation in 27 high-prevalence countries
}

\author{
David Tordrup, ${ }^{1,2}$ Chrissy Bishop, ${ }^{3}$ Nathan Green, ${ }^{4}$ Max Petzold, ${ }^{5}$ \\ Fernando Ruiz Vallejo, ${ }^{6}$ Joshua P Vogel (D) , ${ }^{7}$ Christina Pallitto (i) ${ }^{8}$
}

To cite: Tordrup D, Bishop C, Green $\mathrm{N}$, et al. Economic burden of female genital mutilation in 27 high-prevalence countries. BMJ Global Health 2022;7:e004512. doi:10.1136/ bmjgh-2020-004512

Handling editor Seye Abimbola

- Additional supplemental material is published online only. To view, please visit the journal online (http://dx.doi.org/10. 1136/bmjgh-2020-004512).

Received 24 November 2020 Accepted 17 September 2021

Check for updates

\section{Author(s) (or their} employer(s)) 2022. Re-use permitted under CC BY-NC. No commercial re-use. See rights and permissions. Published by BMJ.

For numbered affiliations see end of article.

Correspondence to Dr Christina Pallitto; pallittoc@who.int

\section{ABSTRACT}

Background Female genital mutilation (FGM) is a traditional harmful practice affecting 200 million women and girls globally. Health complications of FGM occur immediately and over time, and are associated with healthcare costs that are poorly understood. Quantifying the global FGM-related burden is essential for supporting programmes and policies for prevention and mitigation. Methods Health complications of FGM are derived from a meta-analysis and stratified by acute, uro-gynaecological, obstetric and psychological/sexual. Treatment costs are calculated from national cohort models of 27 highburden countries over 30 years. Savings associated with full/partial abandonment are compared with a current incidence reference scenario, assuming no changes in FGM practices.

Results Our model projects an increasing burden of FGM due to population growth. As a reference scenario assuming no change in practices, prevalent cases in 27 countries will rise from 119.4 million (2018) to 205.8 million (2047). Full abandonment could reduce this to 80.0 million (2047), while partial abandonment is insufficient to reduce cases. Current incidence economic burden is US\$1.4 billion/year, rising to US\$2.1 billion/year in 2047. Full abandonment would reduce the future burden to US $\$ 0.8$ billion/year by 2047 .

Conclusion FGM is a human rights violation, a public health issue and a substantial economic burden that can be avoided through effective prevention strategies. While decreasing trends are observed in some countries, these trends are variable and not consistently observed across settings. Additional resources are needed to prevent FGM to avoid human suffering and growing costs. The findings of this study warrant increased political commitment and investment in the abandonment of FGM.

\section{BACKGROUND}

Female genital mutilation (FGM) involves the partial or total removal of external female genitalia or other injury to female genital organs for non-medical reasons. It is usually practised on young girls without consent and is estimated to affect 200 million women and girls alive today. ${ }^{1}$ The practice of FGM is highly concentrated in many African countries and beyond. ${ }^{2}$

\section{WHAT IS ALREADY KNOWN? \\ $\Rightarrow$ Abandonment of female genital mutilation is an in- ternational priority as articulated in the Sustainable Development Goals (target 5.3). In addition to being a violation of human rights and an extreme form of gender discrimination, it also carries high economic costs. \\ WHAT ARE THE NEW FINDINGS? \\ $\Rightarrow$ FGM is associated with increased risks of health complications that can span the life course and cost health systems an estimated 1.4 billion USD per year if reductions in the practice are not achieved. \\ WHAT DO THE NEW FINDINGS IMPLY? \\ $\Rightarrow$ Investment in prevention of FGM can substantially reduce the heatlh care costs of treating its compli- cations, prevent suffering and improve the quality of life of women and girls at-risk of this harmful practice.}

The effects of FGM are physically and emotionally harmful to women and girls, accruing substantial costs to the health system. The immediate health risks of FGM include haemorrhage, shock, extreme pain, genital swelling, infections, urinary complications and problems with wound healing. Longer term consequences to women's health and well-being can include obstetric and gynaecological complications, sexual dysfunction and psychological harm. ${ }^{3}$ WHO has developed evidence-based guidelines, clinical tools and programmatic approaches to strengthen health systems and their ability to provide appropriate care and treatment for the millions of women and girls who have experienced FGM and its consequences, as well as to take actions to prevent the practice. ${ }^{4}$ Despite this, key stakeholders (particularly donors) are looking for evidence that their investments will yield expected outcomes to prevent FGM and the associated short- and long-term consequences. 
Due to population growth, accelerated efforts to stop the practice are needed or the absolute number of affected girls will rise, along with the health burden and health-related costs. ${ }^{5}$ In December 2012 the United Nations General Assembly resolution "Intensifying global efforts for the elimination of female genital mutilations" demonstrated the increased commitment of countries to end this harmful practice. ${ }^{6}$ Efforts are urgently needed to prevent the practice of FGM, as articulated in the Sustainable Development Goals (Target 5.3), as well as to improve the capacity of health systems to respond to FGM and provide appropriate care and treatment. Abandoning FGM both locally and nationally is needed to promote human rights for individuals living in areas where the practice is currently prevalent. ${ }^{6}$

The primary sources of nationally representative prevalence data on FGM are household surveys. Economic impact data, however, are lacking. A 2010 study estimated the obstetric costs of FGM as a percentage of overall government spending across six African countries. The total economic burden of FGM was reported to be $\$ 3.7$ million international dollars across the six countries, and up to $1 \%$ of government health spending on women of reproductive age. ${ }^{7}$ A 2016 study in the UK showed psychological problems and long-term complications of FGM accrued the largest costs, estimated at an annual $£ 100$ million. ${ }^{8}$ Exploring the potential cost savings to health systems which could be expected by implementing interventions to prevent FGM and improve management of its complications is a much needed exercise.

This study estimates the economic burden of FGM and the potential benefits of fully or partially abandoning the practice in 27 high-burden countries. This is achieved by determining the incremental risk of health complications in affected girls and women attributable to FGM; determining the costs of healthcare interventions for managing these complications; and estimating the avoidable cost from fully or partially abandoning the practice of FGM.

\section{METHODS}

\section{Countries}

The analysis included 27 countries, selected on account of having a high burden of FGM and having information on prevalence by type of FGM available. The included countries were: Benin, Burkina Faso, Central African Republic, Côte d'Ivoire, Cameroon, Chad, Djibouti, Egypt, Eritrea, Ethiopia, Ghana, Guinea, Gambia, Guinea-Bissau, Iraq, Kenya, Mali, Mauritania, Niger, Nigeria, Sudan, Senegal, Sierra Leone, Somalia, Togo, United Republic of Tanzania and Yemen. The adult prevalence of FGM and sources of this data are reported in online supplemental appendix 1 .

\section{Model structure}

A dynamic Markov state-transition model with a time horizon of 30 years was constructed. The model states took into account the different life stages in which health complications from FGM may arise (childhood, reproductive age, periods of pregnancy and childbirth, and later life), and were broadly partitioned into individuals unaffected by FGM, individuals affected by type I/II FGM and individuals affected by type III FGM. This stratification of the population by type of FGM allows estimation of costs specific to FGM typology. The model was run separately for each country of the analysis, using national population age structures. States of the model are shown in online supplemental appendix A. The model was implemented in R v 3.6. $1^{9}$ using the HEEMOD package. ${ }^{10}$ The model code and underlying functions were extensively unit tested using RUnit. ${ }^{11}$

\section{Model parameters and population structure}

Probabilities of transitioning between states were derived from a systematic review and meta-analysis of the clinical and epidemiological literature (see table 1) and public databases. Briefly, model population size and age structure were determined by country from the World Population Prospects (WPP) medium variant revision, ${ }^{12}$ using the breakdown by 5 -year age groups. Ageing within the model cohort over the 30-year time horizon was represented by dynamically changing transition probabilities between the $0-14,15-49$ and $50+$ age groups according to the current population age structure. The model population was initiated according to the baseline national age structure and prevalence of FGM in each country. Specifically, the number currently at risk of FGM was the baseline 0-14-year age group minus those already exposed to FGM, while the adult and later life population with FGM was the FGM prevalence multiplied by the 15-49 and 50+ year population size.

For each country, the General Fertility Rate (GFR, total number of live births per 1000 women aged 15-49) was taken from the medium variant revision 2017 of the WPP for the years 2018-2047. GFR was used to determine the annual probability of a childbirth occurring in the cohort of women of reproductive age (15-49 years). The inflow of population to the model was determined by births of the WPP medium variant revision 2017 extrapolation for each year, using a secondary sex ratio (rate at birth) of 0.489 (105 males to 100 females) to determine annual female births. ${ }^{13}$ Further details of model parameters are provided in online supplemental appendix A, while details of model transitions are provided in online supplemental appendix B.

\section{Annual risk of FGM}

The annual risk of being subjected to FGM was estimated from the prevalence of FGM in the adult population by country, recorded in Demographic and Health Survey (DHS) or Multiple Indicator Cluster Survey (MICS) data. The data from these surveys is categorised as 'cut, flesh removed' or 'sewn closed', corresponding to type I/II and type III FGM, respectively. It is a limitation of the data that we cannot fully align the categories from population-based studies with the categorisations measuring health complications, but every 


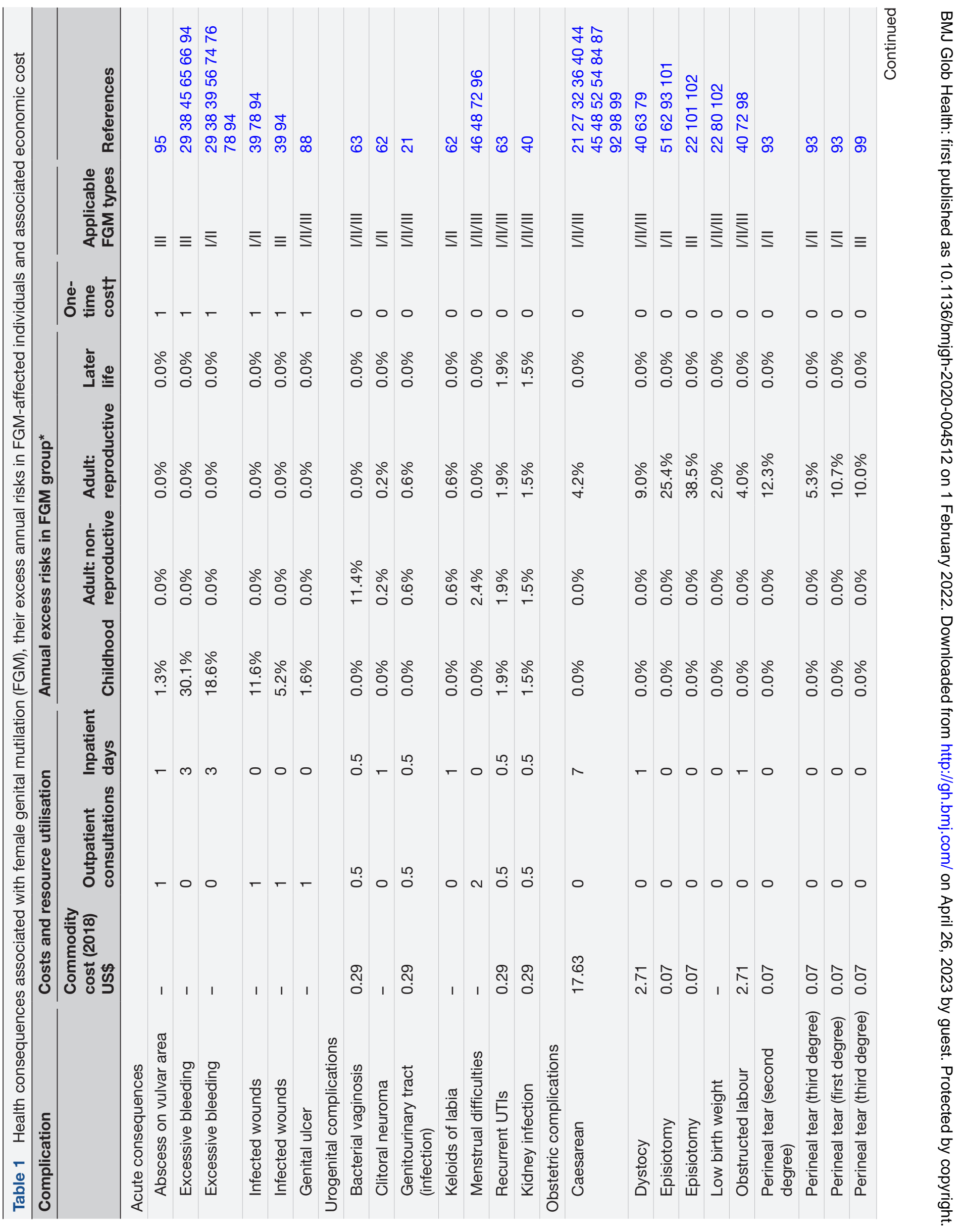




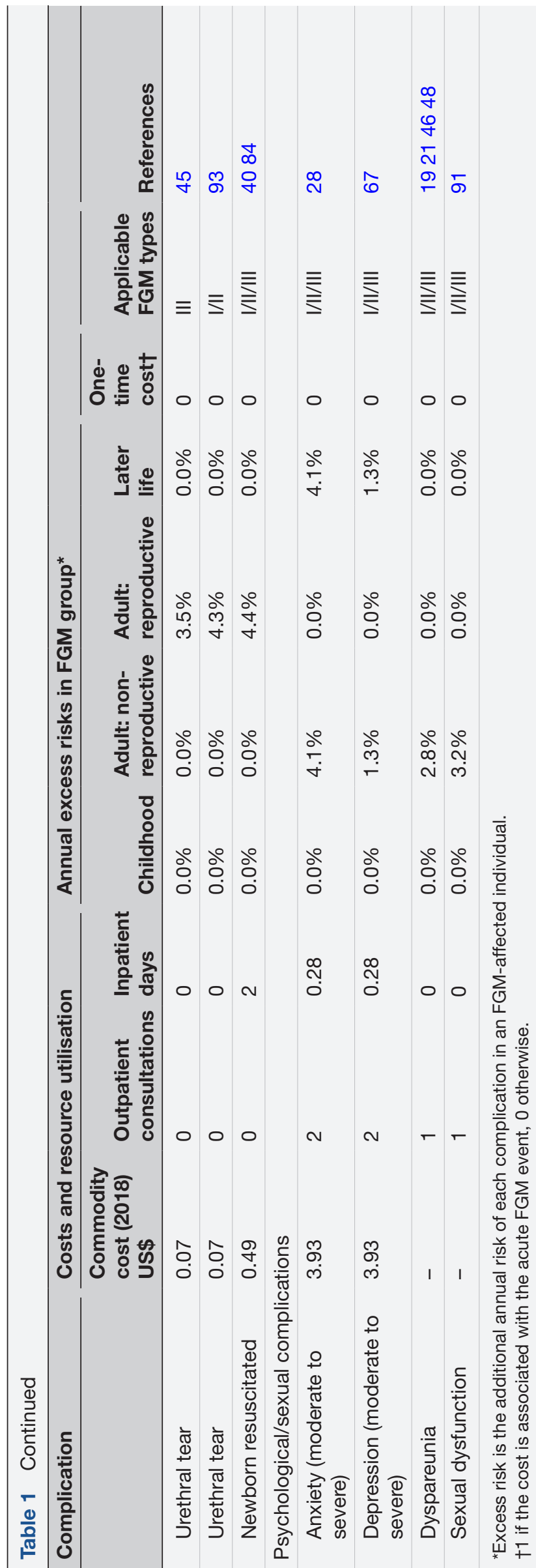

effort was made to ensure that these categories aligned. In some studies measuring associations with complications, a category of 'any FGM' was used given the lack of specificity in the authors' descriptions of FGM typology. Considering the prevalence of FGM at 15 years of age to be a cumulative incidence and thus representing an exponential decay in the unaffected population over 15 years, and assuming all cases of FGM occur in the 0-14-year age group, the annual incidence rate $i$ was derived from the formula for the cumulative distribution function, where $\mathrm{CI}(\mathrm{t})$ is the cumulative probability of being exposed to FGM by year $\mathrm{t}, i$ is the annual incidence rate and $t$ is the time after birth in years (here $\mathrm{CI}(\mathrm{t}=15)=$ prevalence at age 15$)$ :

$$
\begin{gathered}
C I(t)=P(\text { year exposed to } F G M \leq t)=1-e^{-(i t)} \\
i=-\frac{\ln (1-C I(t))}{t}=-\frac{\leftrightarrow \ln (1-\text { prevalence })}{15}
\end{gathered}
$$

Finally, the annual incidence rate was converted to an annual probability using the exponential formula with $\mathrm{t}=1$ denoting a 1-year probability:

$$
\text { annual probability }=1-e^{-(i t)}=1-e^{-i}
$$

Combining the two formulae with the derivation of $i$ for $\mathrm{t}=15$ years yields the following annual risk of FGM in girls aged $0-14$

$$
\text { annual probability }=1-e^{-\frac{\ln (1-\text { prevalence })}{15}}
$$

The annual probability was verified by calculating the evolution of a hypothetical cohort of individuals over 15 years (online supplemental appendix $\mathrm{C}$ )

\section{Background mortality}

Background mortality is incorporated to account for the lifespan during which FGM complications are incurred. Background mortality by age group was derived from the WHO Global Health Observatory indicator LIFE_0000000030, representing the probability of dying between ages $x$ and $x+n$. The most recent year available was used. Five-year mortality rates for the 5-year age buckets reported by the Global Health Observatory were rescaled to 1-year mortality rates in the $0-14,15-49$ and 50-84 age groups of the model. Additional details are provided in online supplemental appendix D.

\section{Intervention effectiveness}

Evidence reviews on what works to reduce FGM $^{14-18}$ reveal a set of promising programmatic activities that may be contributing to observed declines in FGM in some settings. These include community engagement activities, including community dialogues and pledges; working with religious leaders, community leaders, peer educators and other opinion leaders; awareness raising through various communications channels; alternative rites of passage in places where FGM is considered a rite of passage; legislative and policy changes and other accountability mechanisms to penalise the practice of 
FGM; and school-based and health sector-based education initiatives. However, most studies explored the effects of interventions on intermediate outcomes, not on actual reductions in the practice of FGM. Further, most of the interventions were evaluated using pre- and post-test designs or quasi-experimental study designs, and did not have sufficient statistical power to detect changes in outcomes.

Given the limitations in study designs and lack of replication in a range of settings, we did not model incidence reductions as a result of specific interventions in the 27 study countries. Rather, this analysis opted for a continuation of the most recently observed incidence and two hypothetical change scenarios with partial and complete reduction in the incidence of FGM, the latter being an admittedly optimistic scenario but one contemplated in the Sustainable Development Goals. The authors further recognise that FGM prevalence is declining in some countries, while in others it is stable, and in yet others it is increasing. The assumption of continuation of current incidence in the absence of intervention is therefore debatable as it masks country level variation; however, given the variability in these trends and the unpredictability of their trajectory, the current incidence scenario provides a reference scenario against which to compare the projected declines reflected in the hypothetical intervention scenarios.

These hypothetical interventions were assumed to have an effectiveness of 50\% (partial abandonment) and 100\% (full abandonment) in the reduction of the annual risk of FGM for girls aged 0-14. The effect of interventions was assumed to be immediate from the first model year. Due to the irreversible nature of FGM, abandonment of FGM does not eliminate the prevalent population. Consequently, in our model abandonment only affects the number of FGM-affected individuals in the 0-14-year age groups. Abandonment was assumed to reduce the risk of FGM equally among all girls aged $0-14$.

\section{Resource utilisation}

Healthcare utilisation associated with FGM was based on a review and meta-analysis of the literature on clinical complications associated with FGM. ${ }^{19-109}$ All complications for which a significant association with FGM was found, and for which corresponding interventions could be identified, were included in the healthcare utilisation calculations. Random effects meta-analyses were used to estimate the pooled (inverse variance) absolute difference in risk between FGM and non-FGM groups using STATA 16. The economic burden associated with FGM was calculated by linking each clinical complication with a clinical management strategy, sourced from the WHO OneHealth tool list of interventions, ${ }^{110}$ the scientific literature and expert opinion (table 1). As outlined in table 1 , costs associated with specific health complications were assigned to either prevalent type I/II, type III or any FGM (type I/II/III) cases, depending on the associations supported by the literature review.
Country-specific healthcare utilisation rates for specific health complications were not included in the model as these data were not available. Some existing research suggests that women's FGM status can also impact her healthcare utilisation, making her less likely to seek treatment. ${ }^{111}$ However, since most of the data on health risk are based on facility-based studies of women seeking care for some health services (most often maternal or reproductive health services), these studies suggest that women with FGM do seek care for health services and do receive treatments for FGM-related complications even if the proportion of women receiving treatment for particular health complications is not available. The healthcare costs calculated in this study constitute the costs of treating health conditions that may arise from FGM. These costs will be an overestimate of the actual healthcare costs of women seeking care for these conditions since many women will not seek care and health systems in the study countries may not currently routinely diagnose or offer care for these services.

\section{Unit costs}

Unit costs were derived from the WHO OneHealth tool appendix on Intervention Assumptions, ${ }^{110}$ which describes human resources, medicines, consumables and other resources required for individual clinical interventions. Details of these interventions and unit costing are given in online supplemental appendix E. When no information was available in the OneHealth tool for specific complications (genital wounds and ulcers, clitoral neuroma, keloids of labia, post-traumatic stress syndrome), a targeted literature review was carried out to identify published evidence of unit costs (online supplemental appendix F); however, no appropriate unit costs were identified. In such cases, unit costs were based on expert opinion in combination with sources describing the clinical management of these complications. Global unit costs were used for commodities, while countryspecific unit costs from WHO-CHOICE were used for costs of outpatient consultations and inpatient bed days. ${ }^{112}$ As no country costs were available for Somalia, values from the Central African Republic were used as a proxy.

Unit costs were inflated from base year US\$ (2010 for inpatient and outpatient consultation costs; 2015 for commodity costs sourced from OneHealth Tool) to 2018 US\$ using country-specific GDP deflators. ${ }^{113}$

All global unit costs are summarised together with relevant clinical complications in table 1 . Country-specific costs of outpatient consultations and inpatient days are included in online supplemental appendix J.

For reporting, costs are stratified by acute complications (bleeding, abscesses, etc), uro-gynaecological complications (urinary tract infections, neuroma, etc), obstetric and neonatal complications (caesarean sections, dystocy, etc) and psychological/sexual complications (anxiety, depression, etc), as outlined in table 1 . 


\section{Sensitivity analysis}

We undertook one-way deterministic sensitivity analyses using plausible ranges for the parameters anticipated to have a substantial impact on the model results, including annual incidence of different types of FGM, background mortality rates, annual births, and sub-categories of costs: acute complications, infections, scarring and obstetrics (detailed in online supplemental appendix G). Due to lack of data on distribution or plausible ranges of these parameters, we varied point estimates from $0.5 \times$ to $2 \times$ the base case value, except for cost categories where we varied point estimates from $0.25 \times$ to $4 \times$ the base case value. Cost sub-categories were examined in sensitivity analysis in aggregate rather than individual risks and unit costs, due to the many constituent parts of these sub-categories. A total of 27 model parameters were examined, and sensitivity analysis was undertaken at the country level to account for differences in context and country-specific consultation costs. An overview of the parameters varied in the sensitivity analysis and the range is given in online supplemental appendix G.

\section{RESULTS}

Multiple health consequences are associated with FGM. A systematic review and meta-analysis undertaken by WHO has linked FGM with multiple health complications across the life course. An overview of the complications included in this study is given in table $1 .{ }^{109}$ The complications are broadly categorised as acute complications arising directly from FGM, uro-gynaecological complications arising directly in the affected tissue and the broader urogenital system, obstetric complications, and psychological and sexual complications (based on literature identified according to Robbers $e t$ al) ${ }^{109}$

FGM typically occurs in the childhood years and affects individuals across the life course. Figure 1 shows the evolution of adult prevalence of FGM over 30 years for the included countries. To assess the potential impact of reduction in FGM through initiatives to prevent the practice, our model suggests the effect of preventing FGM by $50 \%$ during childhood would reduce the adult prevalence of FGM by a median of 24\% (IQR 22-26\%) across countries over 30 years. Full abandonment of FGM would result in a median reduction in adult prevalence of $55 \%$ (IQR 52-57\%) across countries over 30 years.

In the model, the total economic burden of FGM is a function of both prevalence and population size. Figure 2 outlines the total projected population growth in the 27 countries, along with the projected prevalent cases of FGM in our model. The number of prevalent FGM cases in the current incidence scenario, in which no reductions in FGM occur, follows the same trend as the general population growth, substantially increasing over time from 119.4 million cases at baseline to 205.8 million in 2047 (note that our model does not include all countries for which the global estimate of 200 million cases cited in the literature is derived). A partial abandonment of FGM by $50 \%$ is not sufficient to cause a reduction in prevalent cases over the model time horizon, which in this case results in a total of 154.5 million prevalent cases by 2047. In contrast, full abandonment of FGM does result in a reduction in total prevalent cases from 119.4 million at baseline to 80.0 million in the year 2047 .

Each prevalent case of FGM is associated with increased healthcare utilisation. The projected economic burden of FGM across countries is shown in figure 3. Due to increasing prevalent cases, the annual economic burden in a current incidence scenario is projected to increase steadily over the time horizon, rising from approximately US $\$ 1.4$ billion in 2018 to over US $\$ 2.1$ billion per year in 2047. A partial abandonment by $50 \%$ results in a slower increase towards US $\$ 1.7$ billion per year in 2047. Full elimination of FGM would cause a gradual reduction in the annual economic burden from US $\$ 1.4$ billion in 2018 to US $\$ 0.8$ billion in 2047. Figure 3 also shows the majority of the economic burden is in adults who are not
Current Incidence

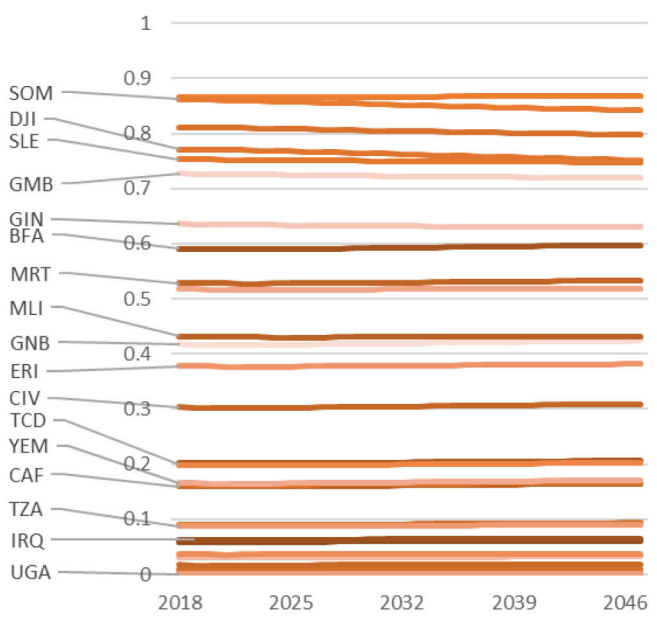

$50 \%$ abandonment

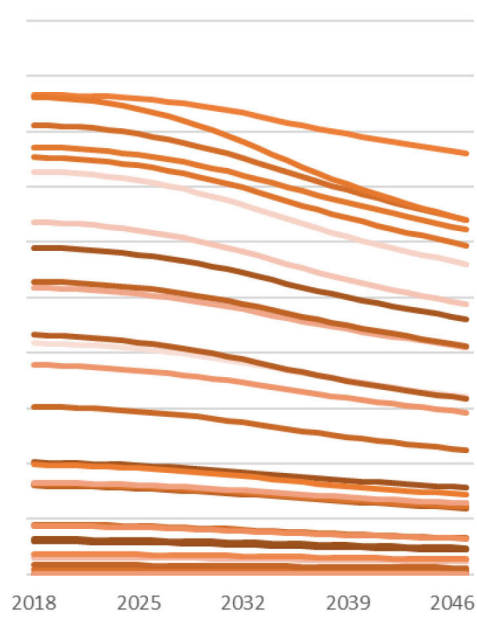

Full abandonment

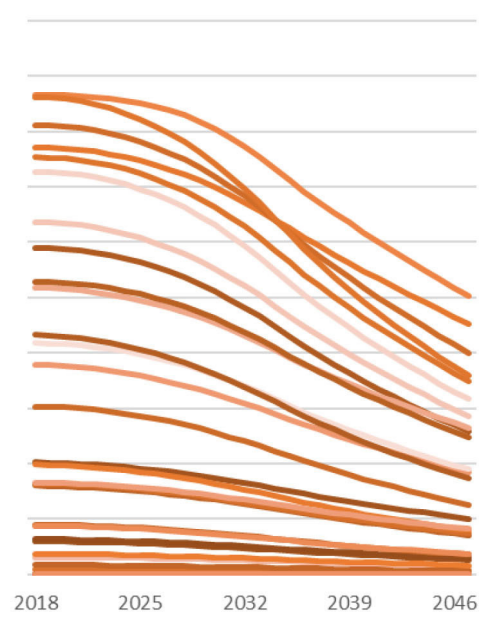

Figure 1 Adult prevalence of female genital mtutilation (FGM) in 27 high-burden countries across three scenarios: current incidence, $50 \%$ abandonment of FGM, and full abandonment of FGM. 


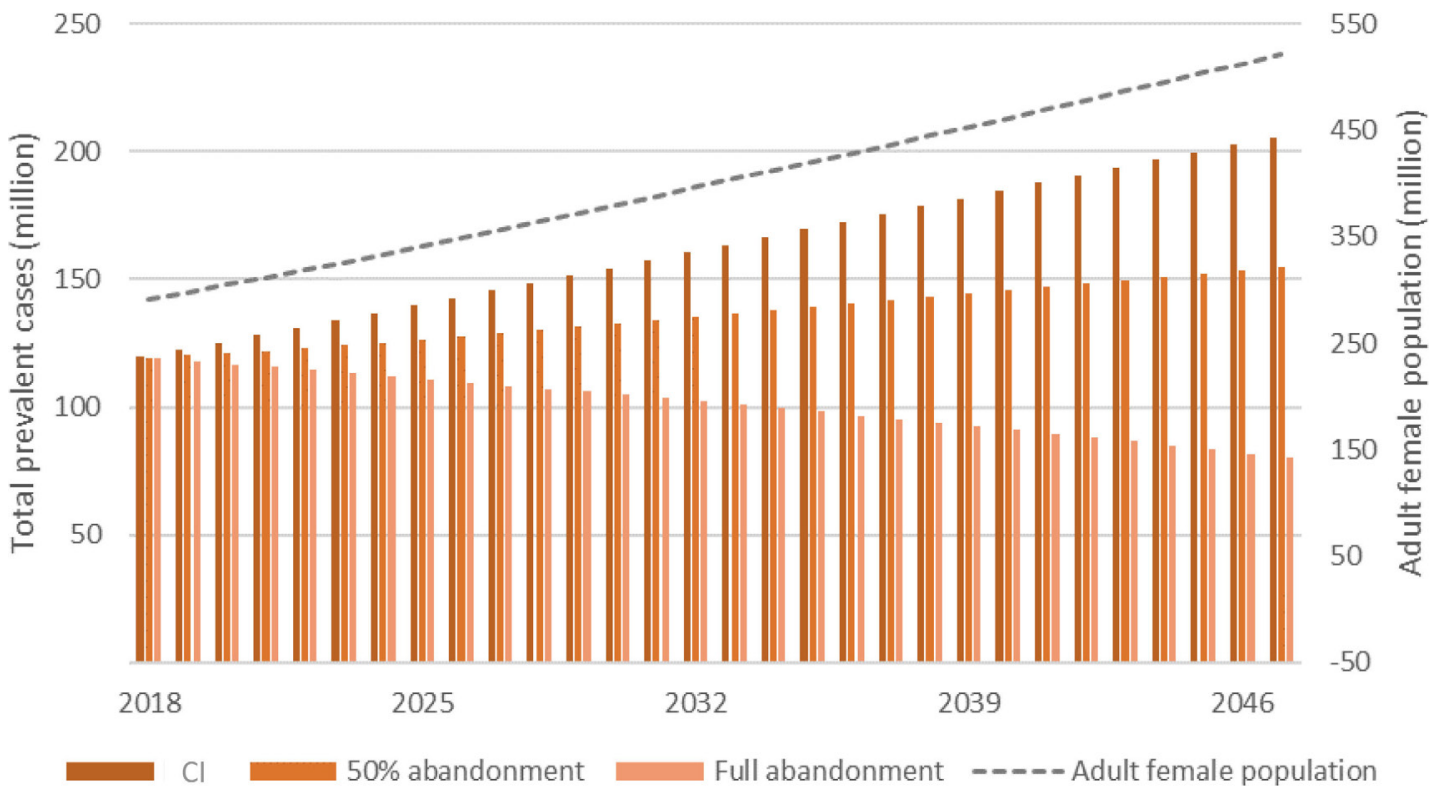

Figure 2 Projected prevalent cases of female genital mutilation (FGM) and total adult female population over the model time horizon across three scenarios: current incidence $(\mathrm{Cl}), 50 \%$ abandonment and full abandonment of FGM.

currently pregnant or giving birth. The prevalent cases and total economic burden per year suggest a burden of US\$10.37-12.46 per prevalent case per year across countries (data not shown). The economic burden per prevalent case depends on a mix of factors including country-specific human resource costs, relative prevalence of FGM types, remaining life expectancy of the FGM affected cohorts, and the relative contribution of new FGM cases (acute complications) versus life-time complications (prevalent cohort).

Costs are incurred across the life course, starting with the acute complications of FGM. Long-term consequences continue into adulthood and during the reproductive cycle, and during the later years of life. The relative contribution to the total economic burden of the four categories of complications examined here is shown in figure 4 for the current incidence scenario over the 30-year time horizon. As also seen in figure 3, the majority of the burden in the current incidence scenario is among adults of reproductive age, within which urogynaecological complications account for the largest burden, followed by psychological/sexual complications. Women who are pregnant and giving birth account for the second largest share of the total economic burden.

The sensitivity analysis by country showed the model was generally sensitive to the annual risk of different types of FGM. This is expected, as the annual risk determines how many new individuals with FGM are present in the population in addition to the prevalent FGM population. Across countries, a 50\% reduction in incidence translated into a decrease of approximately $20 \%$ in total cost. The model was also generally sensitive to cost categories. In the most substantial cases, a $75 \%$ reduction in the cost category estimate was associated with a reduction
Current Incidence

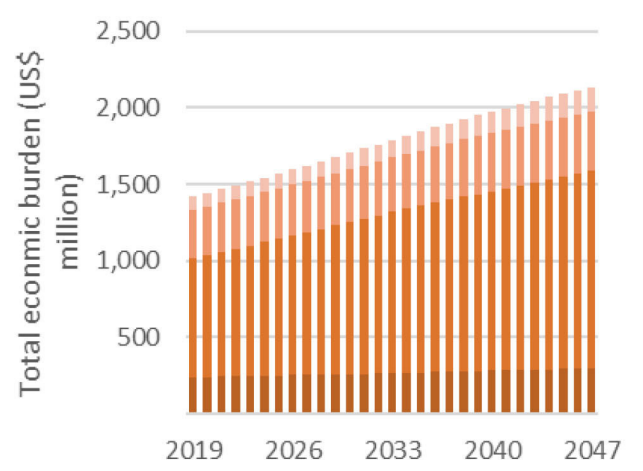

$50 \%$ abandonment

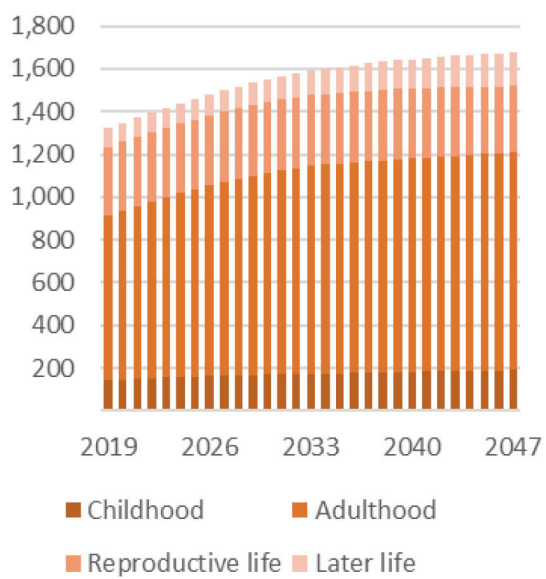

Full abandonment

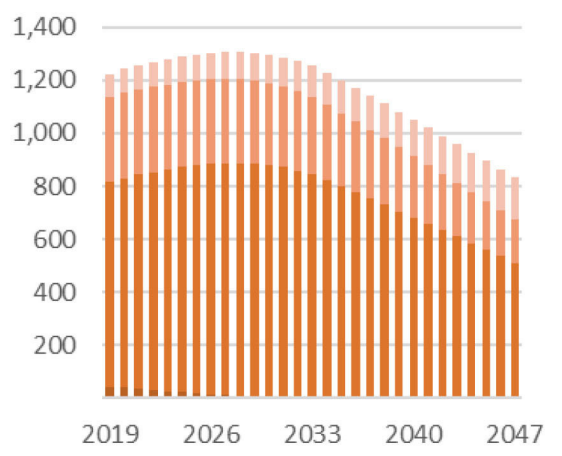

Figure 3 Total economic burden of female genital mutilation (FGM) by stage of life across three scenarios: current incidence, $50 \%$ abandonment of FGM and full abandonment of FGM. 


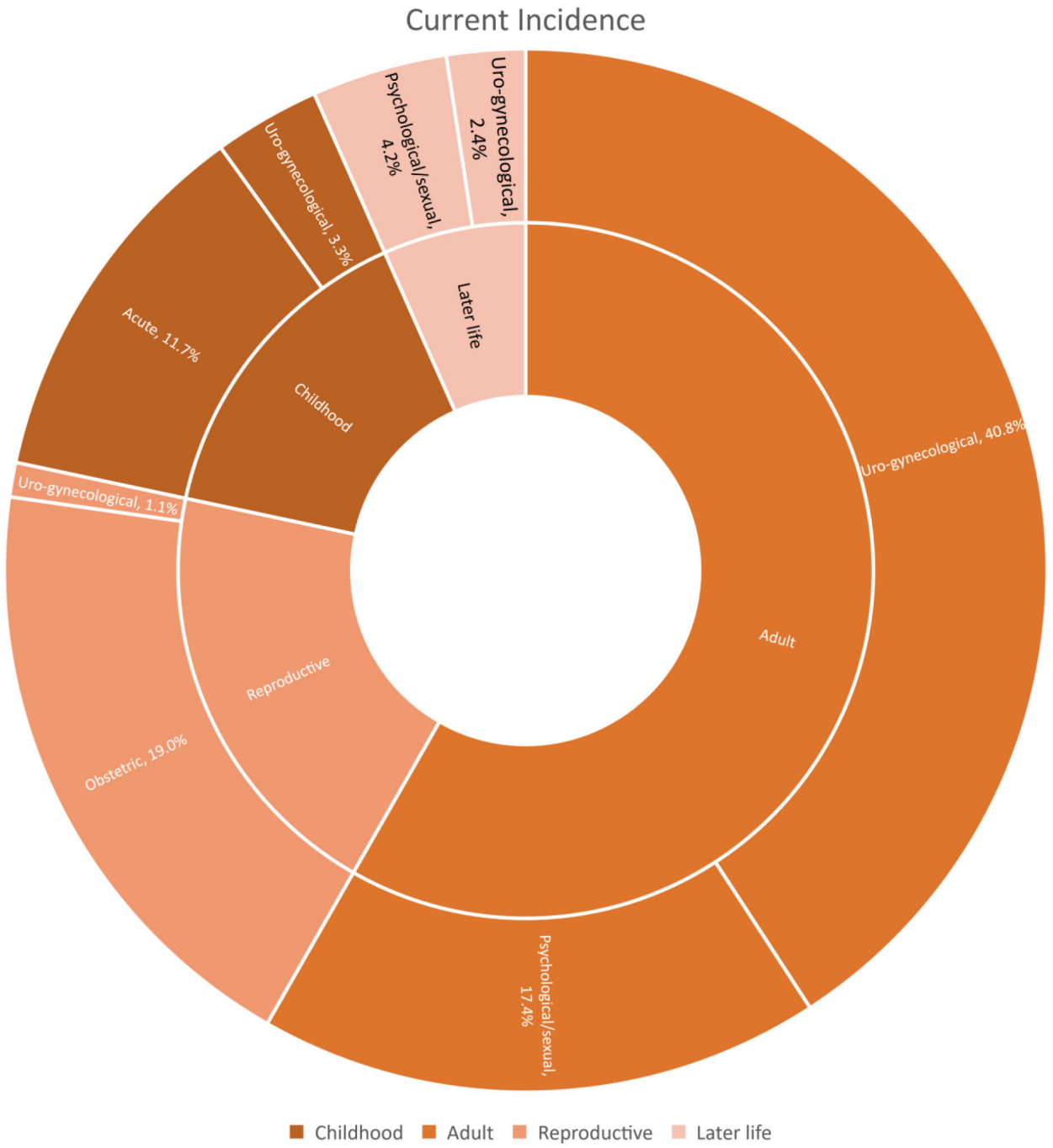

Figure 4 The relative distribution of the total economic burden of female genital mutilation (FGM) across life stages and four types of complications: acute, uro-gynaecological, obstetric and psychological/sexual.

of approximately $30 \%$ in total cost estimate. The parameters examined, as well as plausible ranges applied, are presented in online supplemental appendix G.

\section{DISCUSSION}

The evidence on the economic burden of FGM is scarce and previous estimates have focused on obstetric costs. This study provides the first estimates of costs associated with treating a wider range of health conditions associated with FGM, identified through meta-analyses of data from scientific studies comparing women with and without FGM, by types. Costs have been calculated by year over a 30-year period (2017 to 2047) by applying health risk estimates by type of FGM to FGM prevalence data by type and population data, and assigning cost values to treating these health conditions from existing data sources.

In our projections we find that even a partial abandonment of FGM by $50 \%$ does very little to curb the rise in the economic burden of FGM. Substantial population growth over the next 30 years means the number of cases will continue to rise unless full abandonment is achieved.
However, as a substantial proportion of the economic burden of FGM is concentrated in adults of reproductive age, the economic burden of FGM will continue to be substantial over the next 30 years even if new cases can be prevented.

We find that the economic burden of FGM is currently approximately US $\$ 1.4$ billion per year. Without action, this cost would increase to US $\$ 2.1$ billion per year by 2047 due to the increase in prevalent cases with population growth. In contrast, full abandonment of FGM would lead to a gradual reduction in economic burden, down to approximately US\$800 million per year in 2047 . In these estimates we assume a continuation of current incidence in the absence of interventions as a reference scenario. By extension, if FGM trends were systematically declining in all countries without further intervention, our estimate of US $\$ 2.1$ billion by 2047 in the current incidence scenario would be an upper bound. However, as we have shown a reduction of $50 \%$ in incidence is not sufficient to reduce total cases by 2047 , any such secular 
trends in FGM practices are not likely to meaningfully impact the burden in the medium to long term.

The actual health expenditures of treating FGM and the health utilisation data for treatment of the included health complications are not known. Therefore, the results of this analysis show the estimated costs associated with treating the health burden of FGM. Countries' health financing is likewise not taken into account; health expenditures to treat these complications could potentially include public or private sources as well as out-of-pocket payments.

Recently, estimates have been produced on the costs and impacts of scaling up interventions against FGM. These estimates suggest a total cost of interventions of US $\$ 3.3$ billion from 2020 to 2030 across 31 high burden countries, including prevention through community engagement, mass media and healthcare provider engagement, protection through legislative efforts, treatment of the psychosocial consequences and capacity building among healthcare providers. ${ }^{114}$ This coverage is estimated to avert 4.6 million cases of FGM between 2020 and 2030, and an additional 19.8 million cases during 2031-2050.

In our work, based on population growth and even a $50 \%$ reduction in the practice of FGM, we estimate that around 50 million total prevalent cases could be avoided by 2047 , with a reduction in the annual burden of US $\$ 400$ million per year by 2047. This does not factor in gains in quality of life, economic productivity or other aspects of FGM that can be valued. Although results from these studies cannot be directly compared, these estimates suggest a favourable cost-effectiveness of interventions seeking to end FGM. However, while our analysis suggests a burden of approximately US $\$ 10-12$ per prevalent case of FGM, the cost-effectiveness of interventions in some settings is estimated to be higher at around US $\$ 240$ per case averted. ${ }^{114}$ These observations highlight the importance of identifying interventions that are tailored to specific settings for maximum effectiveness.

There are multiple innovative and promising approaches being implemented in high prevalence countries, and evaluations have shown evidence on changes in intermediate outcomes such as changes in attitudes and reduced support for FGM; improved knowledge about the practice, its harms and its illegality; and intentions to perform FGM. For example, community engagement through information sessions on health, rights and female empowerment, ${ }^{115-117}$ school-based education ${ }^{118}$ and health education within health facilities ${ }^{119}$ as well as communications campaigns using social marketing and other communications approaches ${ }^{120-124}$ show promising results on intermediate outcomes such as knowledge, intentions to cut and reduction in attitudes supportive of FGM. In addition, investing in education of girls and women appears to be associated with decreased support for FGM, and women with higher levels of education were less likely to have their daughters undergo FGM. ${ }^{125-127}$ While these are relevant indicators of social norm change and likely precursors to abandonment, more studies are needed to demonstrate the effectiveness of the approaches in terms of reducing FGM practices, and the replicability of these programmes in different settings. For these reasons, the projections presented on reductions in FGM incidence in the present work are not tied to particular interventions but rather to hypothetical reductions which might be achieved based on a set of context-specific programmatic interventions selected for a particular setting.

\section{Limitations}

A few limitations of the analysis should be noted. Three countries for which FGM prevalence data were available were not included because data on the breakdown of types of FGM were not available. Two of these countries, Indonesia and Liberia, have a high prevalence of FGM (49\% and $44 \%$, respectively), but since different risks are assigned by type of FGM, and since these countries did not have data available by FGM type, they were excluded from the analysis.

The present model uses uniform unit costs of commodities across countries and country-specific unit costs for outpatient consultations and inpatient days. While this is a simplification, we believe the basic commodities required for most of the interventions included here are not subject to large variation in procurement cost and, additionally, the costs of commodities are modest compared with the costs of consultations and inpatient days.

The model makes assumptions around treatmentseeking behaviour. In our work we model the economic impact assuming all healthcare needs result in formal healthcare contact. While we acknowledge that a proportion of healthcare need would result in informal care seeking, or no care seeking at all, we present this analysis in the context of the move towards universal health coverage (UHC). Consequently, our results should be interpreted as the economic burden in a setting with or close to achieving UHC.

We do not model the economic impact of mortality or indirect costs of productivity loss. As such, our model presents only direct costs to the healthcare system associated with FGM and is likely to be an underestimate of the true negative economic and societal impact of FGM.

We recognise that the economic burden will differ between countries, and in particular that our estimates may overestimate costs in settings where rates of FGM are systematically and consistently declining.

Finally, although we include costs related to psychological and sexual health complications, our model does not capture impacts on quality of life or the intangible burden associated with pain, sexual dysfunction or other consequences of FGM. A complementary review of the qualitative literature on FGM and psychosocial well-being discusses these effects. ${ }^{128}$ 


\section{CONCLUSIONS}

Our analysis calculates healthcare costs associated with treating FGM complications but does not consider costs due to loss of productivity, reduced quality of life, mortality and psychosocial complications that might result from FGM and which adversely impact the health and well-being of women and girls who have undergone FGM. As such, this work presents a highly conservative estimate of the total burden of FGM on individuals and society.

Despite these limitations, the analysis provides important arguments for the abandonment of FGM. This traditional harmful practice affects 200 million women and girls alive today and this number will rise without urgent action. The practice violates human rights, causes significant suffering and negative impacts on women's health in the short and long term, and should be abandoned for these reasons alone. Demonstrating that it also increases economic costs to society and women and that these costs will increase over time is yet another reason to accelerate efforts to abandon this harmful practice. These findings support the urgency to end FGM.

\section{Author affiliations}

${ }^{1}$ WHO Collaborating Centre for Pharmaceutical Policy and Regulation, Utrecht, The Netherlands

${ }^{2}$ Triangulate Health Ltd, Doncaster, UK

${ }^{3}$ Independent Consultant, London, UK

${ }^{4}$ University College London, London, UK

${ }^{5}$ School of Public Health and Community Medicine, Institute of Medicine, University of Gothenburg, Gothenburg, Sweden

${ }^{6}$ Institute of Public Health, Pontificia Universidad Javeriana, Bogotá, Colombia ${ }^{7}$ Maternal, Child and Adolescent Health Program, Burnet Institute, Melbourne, Victoria, Australia

${ }^{8}$ UNDP/UNFPA/UNICEF/WHO/World Bank Special Programme of Research, Development and ResearchTraining in Human Reproduction (HRP), Department of Sexual and Reproductive Health and Research, World Health Organization, Geneva, Switzerland

\section{Twitter David Tordrup @dtordrup and Joshua P Vogel @josh_vogel}

Contributors CP and DT designed the study, which was conceptualised and initiated by CP. DT built the model with input from CP and NG. DT coordinated incorporation of model parameters from CP, MP and FRV. NG undertook the targeted literature review for model parameters. MP conducted statistical analysis of health burden data on FGM. FRV created and managed the health burden database based on systematic reviews and screening conducted by FRV, JV and CP. CB extracted and synthesised unit costs from the OneHealth Tool. DT, CB and $\mathrm{CP}$ drafted the manuscript with input from all other authors. All authors reviewed the manuscript prior to submission. $\mathrm{CP}$ is the guarantor of the overall content and controlled the decision to publish.

Funding This study was conducted with the financial support of the Government of Norway, the Government of the United Kingdom and the UNDP-UNFPA-UNICEFWHO-World Bank Special Programme of Research, Development and Research Training in Human Reproduction (HRP), a co-sponsored programme executed by the World Health Organization (WHO).

Patient consent for publication Not applicable.

Provenance and peer review Not commissioned; externally peer reviewed.

Data availability statement All data relevant to the study are included in the article or uploaded as supplementary information. All data provided as supplementary information.

Supplemental material This content has been supplied by the author(s). It has not been vetted by BMJ Publishing Group Limited (BMJ) and may not have been peer-reviewed. Any opinions or recommendations discussed are solely those of the author(s) and are not endorsed by BMJ. BMJ disclaims all liability and responsibility arising from any reliance placed on the content. Where the content includes any translated material, BMJ does not warrant the accuracy and reliability of the translations (including but not limited to local regulations, clinical guidelines, terminology, drug names and drug dosages), and is not responsible for any error and/or omissions arising from translation and adaptation or otherwise.

Open access This is an open access article distributed in accordance with the Creative Commons Attribution Non Commercial (CC BY-NC 4.0) license, which permits others to distribute, remix, adapt, build upon this work non-commercially, and license their derivative works on different terms, provided the original work is properly cited, appropriate credit is given, any changes made indicated, and the use is non-commercial. See: http://creativecommons.org/licenses/by-nc/4.0/.

Author note The authors alone are responsible for the views expressed in this article and they do not necessarily represent the views, decisions or policies of the institutions with which they are affiliated.

\section{ORCID iDs}

Joshua P Vogel http://orcid.org/0000-0002-3214-7096

Christina Pallitto http://orcid.org/0000-0002-7779-9303

\section{REFERENCES}

1 United Nations Children's Fund (UNICEF). Female genital mutilation, 2021United Nations Children's Fund (UNICEF). Available: https://data.unicef.org/topic/child-protection/femalegenital-mutilation/ [Accessed 16 November 2021].

2 UNICEF. Female Genital Mutilation/Cutting: A statistical overview and exploration of the dynamics of change. New York UNICEF; 2013.

3 World Health Organization. Health risks of female genital mutilation, 2021. Available: https://www.who.int/teams/sexualand-reproductive-health-and-research-(srh)/areas-of-work/ female-genital-mutilation/health-risks-of-female-genital-mutilation [Accessed 16 November 2021].

4 World Health Organization. Female genital mutilation: fact sheet. Geneva: WHO; 2020. https://www.who.int/news-room/fact-sheets/ detail/female-genital-mutilation [Accessed 16 November 2021].

5 United Nations Population Fund (UNFPA). Bending the curve: FGM trends we AIM to change. New York: UNFPA; 2018. https:// www.unfpa.org/sites/default/files/resource-pdf/18-053_FGMInfographic-2018-02-05-1804.pdf [Accessed 16 November 2021].

6 Bewley S, Creighton S, Momoh C. Female genital mutilation. BMJ 2010;340:c2728.

7 Bishai D, Bonnenfant Y-T, Darwish M, et al. Estimating the obstetric costs of female genital mutilation in six African countries. Bull World Health Organ 2010;88:281-8.

$8 \mathrm{Hex}$ N, Hanlon J, Wright D. Estimating the costs of female genital mutilation services to the NHS Partnership for Responsive Policy Analysis and Research; 2016. https://www.york.ac.uk/media/ healthsciences/images/research/prepare/reportsandtheircover images/EstimatingCostsOfFGMServices.pdf [Accessed $15 \mathrm{Nov}$ 2021].

9 R Core Team. R: a language and environment for statistical computing, 2019.

10 Filipović-Pierucci A, Zarca K, Durand-Zaleski I. Markov models for health economic evaluation: the R package heemod. ArXiv 2017.

11 Burger M, Juenemann K, Koenig T. RUnit: $R$ unit test framework, 2018.

12 United Nations. World population prospects 2017 revision, 2017. Available: https://population.un.org/wpp/Download/Standard/ Population/

13 World Health Organization. Sex ratio. Available: http://origin.searo. who.int/entity/health_situation_trends/data/chi/sex-ratio/en/

14 Baillot H, Murray N, Connelly E, et al. Addressing female genital mutilation in Europe: a scoping review of approaches to participation, prevention, protection, and provision of services. Int $J$ Equity Health 2018;17:1-15.

15 Berg RC, Denison EM. A realist synthesis of controlled studies to determine the effectiveness of interventions to prevent genital cutting of girls. Paediatr Int Child Health 2013;33:322-33.

16 Johansen REB, Diop NJ, Laverack G. What works and what does not: a discussion of popular approaches for the abandonment of female genital mutilation. Obstet Gynecol Int 2013;2013:1-10.

17 Feldman-Jacobs C. Ending female genital mutilation/cutting: lessons from a decade of progress, 2013. Available: http//www. prb. org/Publications/Reports/2014/progress-ending-fgm. aspx 
18 Waigwa S, Doos L, Bradbury-Jones C, et al. Effectiveness of health education as an intervention designed to prevent female genital mutilation/cutting (FGM/C): a systematic review. Reprod Health 2018;15:62.

19 Abdel-Aleem MA, Elkady MM, Hilmy YA. The relationship between female genital cutting and sexual problems experienced in the first two months of marriage. Int J Gynecol Obstet 2016;132:305-8.

20 Abdulcadir J, Botsikas D, Bolmont M, et al. Sexual anatomy and function in women with and without genital mutilation: a crosssectional study. J Sex Med 2016;13:226-37.

21 Andro A, Cambois E, Lesclingand M. Long-term consequences of female genital mutilation in a European context: self perceived health of FGM women compared to non-FGM women. Soc Sci Med 2014;106:177-84.

22 Anikwe CC, Ejikeme BN, Obiechina NJ, et al. Female genital mutilation and obstetric outcome: a cross-sectional comparative study in a tertiary hospital in Abakaliki South East Nigeria. Eur J Obstet Gynecol Reprod Biol X 2019;1:100005.

23 Anis TH, Aboul Gheit S, Awad HH, et al. Effects of female genital cutting on the sexual function of Egyptian women. A crosssectional study. J Sex Med 2012;9:2682-92.

24 Applebaum J, Cohen H, Matar M, et al. Symptoms of posttraumatic stress disorder after ritual female genital surgery among bedouin in Israel: myth or reality? Prim Care Companion J Clin Psychiatry 2008;10:453-6.

25 Arafa AE, Elbahrawe RS, Shawky SM, et al. Epidemiological and gynecological correlates with female genital mutilation among BeniSuef university students; cross sectional study. Middle East Fertil Soc $J$ 2018;23:184-8.

26 Ali HAAEW, Arafa AE, El Fattah Abd Allah Shehata NA, et al. Prevalence of female circumcision among young women in BeniSuef, Egypt: a cross-sectional study. J Pediatr Adolesc Gynecol 2018;31:571-4.

27 Balachandran AA, Duvalla S, Sultan AH, et al. Are obstetric outcomes affected by female genital mutilation? Int Urogynecol $J$ 2018;29:339-44.

28 Behrendt A, Moritz S. After female genital mutilation. Am J Psychiatry 2005;162:1000-2.

29 Institut National de la Statistique et de l'Analyse Économique (INSAE) et ORC Macro. Enquête Démographique et de Santé au Bénin 2001. Calverton, Maryland, USA: INSAE et ORC Macro, 2002.

30 Institut National de la Statistique et de l'Analyse Économique (INSAE) [Bénin] et Macro International Inc. Enquête Démographique et de Santé, Bénin 2006. Calverton, Maryland, USA: INSAE et Macro International Inc, 2007.

31 Adinma Jl. Current status of female circumcision among Nigerian Igbos. West Afr J Med 1997;16:227-31.

32 Berardi JC, Teillet JE, Godard J. Conséquences obstétricales de l'excision féminine: étude chez 71 femmes africaines excisées. $J$ Gynécol Obs Biol Reprod 1985;14:743-6.

33 Biglu M-H, Farnam A, Abotalebi P, et al. Effect of female genital mutilation/cutting on sexual functions. Sex Reprod Healthc 2016;10:3-8.

34 Birge O, Arslan D, Ozbey EG. Which type of circumcision is more harmful to female sexual functions? Clin Exp Obstet Gynecol Int $J$ 2010;44:691-4.

35 Boghossian AS, Freebody J, Moses R, et al. Risk assessment for antenatal depression among women who have undergone female genital mutilation or cutting: are we missing the mark? Aust $N Z J$ Obstet Gynaecol 2020;60:1-6.

36 Bohoussou KM, Anongba S, Djanhan Y. Complications gynecologiques, medicales et obstetricales de l'excision rituelle. Afr Med 1986;25:160-2.

37 Brewer DD, Potterat JJ, Roberts JM, et al. Male and female circumcision associated with prevalent HIV infection in virgins and adolescents in Kenya, Lesotho, and Tanzania. Ann. Epidemiol. 2007;17:217.e1-217.e12.

38 Insitut National de la Statistique et de la Démographie (INSD) et ORC Macro. Enquête démographique et de santé Du Burkina Faso 2003. Calverton, Maryland, USA: INSD et ORC Macro, 2004.

39 Ouagadjio B, Nodjimadji K, Bagamla T, et al. Enquête démographique et de santé Tchad 2004. Calverton, Maryland, USA: INSEED et ORC Macro, 2005.

40 Chibber R, El-Saleh E, El Harmi J. Female circumcision: obstetrical and psychological sequelae continues unabated in the 21st century. J Matern Fetal Neonatal Med 2011;24:833-6.

41 Chu T, Akinsulure-Smith AM. Health outcomes and attitudes toward female genital cutting in a community-based sample of West African immigrant women from high-prevalence countries in New York City. J Aggress Maltreatment Trauma 2016;25:63-83.
42 Ahmed MR, Shaaban MM, Meky HK, et al. Psychological impact of female genital mutilation among adolescent Egyptian girls: a cross-sectional study. Eur J Contracept Reprod Health Care 2017;22:280-5.

43 Daneshkhah F, Allahverdipour $\mathrm{H}$, Jahangiri L, et al. Sexual function, mental well-being and quality of life among Kurdish circumcised women in Iran. Iran J Public Health 2017;46:1265-74.

44 Davis G, Jellins J. Female genital mutilation: obstetric outcomes in metropolitan Sydney. Aust N Z J Obstet Gynaecol 2019;59:312-6.

45 De Silva S. Obstetric sequelae of female circumcision. Eur J Obstet Gynecol Reprod Biol 1989;32:233-40.

46 el-Defrawi MH, Lotfy G, Dandash KF, et al. Female genital mutilation and its psychosexual impact. J Sex Marital Ther 2001;27:465-73.

47 Elnashar AM, El-Dien Ibrahim M, El-Desoky MM, et al. Female sexual dysfunction in lower Egypt. BJOG 2007;114:201-6.

48 Elnashar A, Abdelhady R. The impact of female genital cutting on health of newly married women. Int J Gynaecol Obstet 2007;97:238-44.

49 Esho T, Kimani S, Nyamongo I, et al. The 'heat' goes away: sexual disorders of married women with female genital mutilation/cutting in Kenya. Reprod Health 2017;14:164.

50 Essén B, Sjöberg N-O, Gudmundsson S, et al. No association between female circumcision and prolonged labour: a case control study of immigrant women giving birth in Sweden. Eur J Obstet Gynecol Reprod Biol 2005;121:182-5.

51 Frega A, Puzio G, Maniglio P, et al. Obstetric and neonatal outcomes of women with FGM I and II in San Camillo Hospital, Burkina Faso. Arch Gynecol Obstet 2013;288:513-9.

52 Gebremicheal K, Alemseged F, Ewunetu H, et al. Sequela of female genital mutilation on birth outcomes in Jijiga town, Ethiopian Somali region: a prospective cohort study. BMC Pregnancy Childbirth 2018:18:305

53 Akinsulure-Smith AM. Exploring female genital cutting among West African immigrants. J Immigr Minor Health 2014;16:559-61.

54 Gudu W, Abdulahi M. Labor, delivery and postpartum complications in nulliparous women with female genital mutilation admitted to KARAMARA Hospital. Ethiop Med J 2017;55:11-17.

55 Direction Nationale de la Statistique [Guinée] et Macro International Inc. Enquête Démographique et de Santé, Guinée 1999. Calverton, Maryland, USA: Direction Nationale de la Statistique et Macro International Inc, 2000.

56 Direction Nationale de la Statistique (DNS) (Guinée) et ORC Macro. Enquête Démographique et de Santé, Guinée 2005. Calverton, Maryland, USA: DNS et ORC Macro, 2006.

57 Hakim LY. Impact of female genital mutilation on maternal and neonatal outcomes during parturition. East Afr Med $\mathrm{J}$ 2001;78:255-8.

58 Holmgren B, da Silva Z, Larsen O, et al. Dual infections with HIV-1, HIV-2 and HTLV-I are more common in older women than in men in Guinea-Bissau. AIDS 2003;17:241-53.

59 Ibrahim ZM, Ahmed MR, Sayed Ahmed WA. Prevalence and risk factors for female sexual dysfunction among Egyptian women. Arch Gynecol Obstet 2013;287:1173-80.

60 Ismail SA, Abbas AM, Habib D, et al. Effect of female genital mutilation/cutting; types I and II on sexual function: case-controlled study. Reprod Health 2017;14:108.

61 Kanki P, M'Boup S, Marlink R, et al. Prevalence and risk determinants of human immunodeficiency virus type 2 (HIV-2) and human immunodeficiency virus type 1 (HIV-1) in West African female prostitutes. Am J Epidemiol 1992;136:895-907.

62 Kaplan A, Forbes M, Bonhoure I, et al. Female genital mutilation/ cutting in the Gambia: long-term health consequences and complications during delivery and for the newborn. Int $J$ Womens Health 2013;5:323-31.

63 Kasim K, Shaaban S. Impacts of female genital mutilation on women's reproductive health. J Community Med Health Educ 2012;2:1-4.

64 Almroth L, Bedri H, El Musharaf S, et al. Urogenital complications among girls with genital mutilation: a hospital-based study in Khartoum. Afr J Reprod Health 2005;9:118-24.

65 Khodabakhshi Koolaee A, Pourebrahim T, Mohammadmoradi B, et al. The comparison of marital satisfaction and mental health in genital mutilated females and non-genital mutilated females. Int $J$ High Risk Behav Addict 2012;1:115-20.

66 Kizilhan J. I. Impact of psychological disorders after female genital mutilation among Kurdish girls in Northern Iraq. Eur J Psychiatry 2011;25:92-100.

67 Köbach A, Ruf-Leuschner M, Elbert T. Psychopathological sequelae of female genital mutilation and their neuroendocrinological associations. BMC Psychiatry 2018;18:187. 
68 Larsen U, Okonofua FE. Female circumcision and obstetric complications. Int J Gynaecol Obstet 2002;77:255-65.

69 Larsen U, Yan S. Does female circumcision affect infertility and fertility? A study of the central African Republic, Côte d'Ivoire, and Tanzania. Demography 2000;37:313-21.

70 Larsen $U$. The effects of type of female circumcision on infertility and fertility in Sudan. J Biosoc Sci 2002;34:363-77.

71 Maheu-Giroux M, Filippi V, Maulet N, et al. Risk factors for vaginal fistula symptoms in Sub-Saharan Africa: a pooled analysis of national household survey data. BMC Preg Child 2016;16:82.

72 Mahmoud MIH. Effect of female genital mutilation on female sexual function, Alexandria, Egypt. Alexandria J Med 2016;52:55-9.

73 Mahmoudi O, Hosseini E. Psychosexual complications of female genital mutilation for couples: a comparative study. J Kermanshah Univ Med Sci 2017;20:135-40.

74 Cellule de Planification et de Statistique du Ministère de la Santé (CPS/MS), Direction Nationale de la Statistique et de I'Informatique (DNSI) et ORC Macro.. Enquête Démographique et de Santé Au Mali. Calverton, Maryland, USA:CPS/MS, DNSI et ORC Macro; 2002. https://www.dhsprogram.com/pubs/pdf/FR134/FR134ML01.pdf [Accessed 16 November 2021].

75 Almroth L, Elmusharaf S, El Hadi N, et al. Primary infertility after genital mutilation in girlhood in Sudan: a case-control study. Lancet 2005;366:385-91.

76 Cellule de Planification et de Statistique du Ministère de la Santé (CPS/MS), D. N. de la, Statistique et de l'Informatique du Ministère de l'Économie, de l'Industrie et du C. \& 2007., (DNSI/MEIC) et Macro International Inc. Enquête Démographique et de Santé Du Mali 2006. Calverton, Maryland, USA: CPS/DNSI et Macro International Inc, 2006.

77 Maslovskaya O, Brown JJ, Padmadas SS. Disentangling the complex association between female genital cutting and HIV among Kenyan women. J Biosoc Sci 2009;41:815-30.

78 Office National de la Statistique (ONS) [Mauritanie] et ORC Macro. Enquête Démographique et de Santé Mauritanie 2000-2001. Calverton, Maryland, USA: ONS et ORC Macro, 2000.

79 Millogo-Traore F, Kaba STA, Thieba B, et al. Pronostic maternel et fœtal au cours de l'accouchement chez la femme excisée. J Gynecol Obstet Biol Reprod 2007;36:393-8.

80 Minsart A-F, N'guyen T-S, Ali Hadji R, et al. Maternal infibulation and obstetrical outcome in Djibouti. J Matern Fetal Neonatal Med 2015;28:1741-6.

81 Mohammed GF, Hassan MM, Eyada MM. Female genital mutilation/ cutting: will it continue? J Sex Med 2014;11:2756-63.

82 Morison L, Scherf C, Ekpo G, et al. The long-term reproductive health consequences of female genital cutting in rural Gambia: a community-based survey. Trop Med Int Health 2001;6:643-53.

83 Msuya SE, Mbizvo E, Hussain A, et al. Female genital cutting in Kilimanjaro, Tanzania: changing attitudes? Trop Med Int Health 2002;7:159-65

84 Ndiaye P. Mutilation génitale féminine et complications de I' accouchement dans la province de Gourma (Burkina Faso). Sante Publique 2010;22:563-70.

85 Odoi A, Brody SP, Elkins TE. Female genital mutilation in rural Ghana, West Africa. Int J Gynaecol Obstet 1997;56:179-80.

86 Alsibiani SA, Rouzi AA. Sexual function in women with female genital mutilation. Fertil Steril 2010;93:722-4.

87 Oduro A, Ansah P, Hodgson A, et al. Trends in the prevalence of female genital mutilation and its effect on delivery outcomes in the Kassena-Nankana district of northern Ghana. Ghana Med J 2006;40:87-92.

88 Okonofu FE, Larsen U, Oronsaye F, et al. The association between female genital cutting and correlates of sexual and gynaecological morbidity in Edo state, Nigeria. BJOG 2002;109:1089-96.

89 Oyefara JL. Female genital mutilation (FGM) and sexual functioning of married women in Oworonshoki Community, Lagos State, Nigeria. Etude la Popul Africaine 2015;29:1526-40.

90 Pépin J, Plamondon M, Alves AC, et al. Parenteral transmission during excision and treatment of tuberculosis and trypanosomiasis may be responsible for the HIV-2 epidemic in Guinea-Bissau. AIDS 2006;20:1303-11.

91 Abdel Raheem TA, El-tahalawi SMR, Abo Raia NM, et al. The effect of female genital mutilation on couple sexual function. Int $J$ Community Med Public Health 2018;5:905-11.

92 Rodriguez MI, Say L, Abdulcadir J, et al. Clinical indications for cesarean delivery among women living with female genital mutilation. Int J Gynaecol Obstet 2017;139:21-7.

93 Saleh WF, Torky HA, Youssef MA, et al. Effect of female genital cutting performed by health care professionals on labor complications in Egyptian women: a prospective cohort study. J Perinat Med 2018;46:419-24.
94 Ndiaye S, Ayad M. Enquête démographique et de santé au Sénégal 2005. Centre de recherche pour le développement humain [Sénégal] and ORC Macro. Calverton, Maryland, USA: Centre de Recherche pour le Développement Humain [Sénégal] et ORC Macro, 2006.

95 Shandall AA. Circumcision and infibulation of females: a general consideration of the problem and a clinical study of the complications in Sudanese women. Sudan Med J 1967;5:178-212.

96 Shiferaw MT, Wubshet M, Tegabu D. Menstrual problems and associated factors among students of Bahir Dar University, Amhara National Regional State, Ethiopia: a cross-sectional survey. Pan Afr Med J 2014:17:246.

97 Amin MM, Rasheed S, Salem E. Lower urinary tract symptoms following female genital mutilation. Int $J$ Gynaecol Obstet 2013;123:21-3.

98 Slanger TE, Snow RC, Okonofua FE. The impact of female genital cutting on first delivery in Southwest Nigeria. Stud Fam Plann 2002;33:173-84.

99 Théra T, Kouma A, Touré M, et al. Complications obstétricales des mutilations génitales en milieu rural Malien. J Gynécologie Obs Biol Reprod 2015;44:276-9.

100 Ahmed UT, Ismail S, Kunna A. Impact of female genital mutilation on second stage of labour in primigravida at Omdurman maternity Hospital, Sudan 2010. Sudan Journal of Medical Sciences

101 Varol N, Dawson A, Turkmani S, et al. Obstetric outcomes for women with female genital mutilation at an Australian hospital, 2006-2012: a descriptive study. BMC Preg Child 2016;16:1-11.

102 WHO study group on female genital mutilation and obstetric outcome, Banks E, Meirik O, et al. Female genital mutilation and obstetric outcome: WHO collaborative prospective study in six African countries. Lancet 2006;367:1835-41.

103 Wuest S, Raio L, Wyssmueller D, et al. Effects of female genital mutilation on birth outcomes in Switzerland. BJOG 2009;116:1204-9.

104 Yassin K, Idris HA, Ali AA. Characteristics of female sexual dysfunctions and obstetric complications related to female genital mutilation in Omdurman maternity hospital, Sudan. Reprod Health 2018;15:7.

$105 \mathrm{CSO}$ and MI. Yemen demographic and maternal and child survey 1997. Calverton, Maryland, USA: CSO and MI, 1998.

106 Yount KM, Abraham BK. Female genital cutting and HIV/AIDS among Kenyan women. Stud Fam Plann 2007;38:73-88.

107 Zayed AA, Ali AA. Abusing female children by circumcision is continued in Egypt. J Forensic Leg Med 2012;19:196-200.

108 Andersson SHA, Rymer J, Joyce DW, et al. Sexual quality of life in women who have undergone female genital mutilation: a casecontrol study. BJOG 2012;119:1606-11.

109 Robbers G, Vogel JP, Vallejo FR, et al. The health consequences of female genital mutilation: protocol for a systematic review and meta-analysis. PROSPERO CRD42020164693, 2020. Available: https://www.crd.york.ac.uk/prospero/display_record.php?ID= CRD42020164693

110 Avenir. OneHealth intervention input manual. OneHealth tool, 2016. Available: http://avenirhealth.org/Download/Spectrum/Manuals/ Treatment Assumptions 2016 110.pdf

111 Kimani S, Kabiru CW, Muteshi J, et al. Exploring barriers to seeking health care among Kenyan Somali women with female genital mutilation: a qualitative study. BMC Int Health Hum Rights 2020;20:3.

112 WHO-CHOICE. WHO Health service delivery costs. Available: https://www.who.int/choice/cost-effectiveness/inputs/health service/en/

113 The World Bank. Inflation, GDP deflator: linked series (annual \%) data. Available: https://data.worldbank.org/indicator/NY.GDP.DEFL. KD.ZG.AD

114 Katz I, Sanders R, Carvalho MN, et al. Cost and impact of scaling up female genital mutilation prevention and care programs: estimated resource requirements and impact on incidence and prevalence. PLoS One 2021;16:e0244946.

115 Diop NJ, Askew I. The effectiveness of a community-based education program on abandoning female genital mutilation/cutting in Senegal. Stud Fam Plann 2009;40:307-18.

116 UNICEF. Long-term evaluation of the Tostan programme in Senegal: Kolda, Thiès and Fatick regions. Stat Monit Sect 2008

117 Asekun-Olarinmoye EO, Amusan OA. The impact of health education on attitudes towards female genital mutilation (FGM) in a rural Nigerian community. Eur $J$ Contracept Reprod Health Care 2008:13:289-97.

118 Mahgoub E, Nimir M, Abdalla S, et al. Effects of school-based health education on attitudes of female students towards female genital mutilation in Sudan. East Mediterr Health J 2019;25:406-12. 
119 Ekwueme OC, Ezegwui HU, Ezeoke U. Dispelling the myths and beliefs toward female genital cutting of woman: assessing general outpatient services at a tertiary health institution in Enugu state, Nigeria. East Afr J Public Health 2010;7:64-7.

120 UNICEF. The dynamics of social change towards the abandonment of female genital mutilation/cutting in five African countries. Innocenti Insight 2010.

121 Suzuki C, Meekers D. Determinants of support for female genital cutting among ever-married women in Egypt. Glob Public Health 2008;3:383-98.

122 Evans WD, Donahue C, Snider J, et al. The Saleema initiative in Sudan to abandon female genital mutilation: outcomes and dose response effects. PLoS One 2019;14:e0213380.

123 Hussein SA, Ghattass S. 'No to circumcision': the road to effective social marketing campaigns in Egypt. New York Population Council. Evidence to End FGM/C: Research to Help Girls and Women Thrive; 2019. https://knowledgecommons.popcouncil.org/ departments_sbsr-rh/1011/
124 Barsoum G, Rifaat N, El-Gibaly OPoverty, Gender, and Youth Working Paper no. 22.. National efforts toward FGM-free villages in Egypt: the evidence of impact. New York Population Council; 2011. https://knowledgecommons.popcouncil.org/departments_sbsrpgy/152/

125 Rawat $\mathrm{R}$. The association between economic development, education and FGM in six selected African countries. Afr $J$ Midwifery Womens Health 2017;11:137-46.

126 Ameyaw EK, Tetteh JK, Armah-Ansah EK, et al. Female genital mutilation/cutting in Sierra Leone: are educated women intending to circumcise their daughters? BMC Int Health Hum Rights 2020;20:19.

127 Afifi M. Women's empowerment and the intention to continue the practice of female genital cutting in Egypt. Arch Iran Med 2009;12:154-60.

128 O'Neill S, Pallitto C. The consequences of female genital mutilation on psycho-social well-being: a systematic review of qualitative research. Qual Health Res 2021;31:1738-50. 